\title{
COMUNIDADES QUILOMBOLAS DO PORTAL DO SERTÃO DA BAHIA: A LUTA ENTRE O RECONHECIMENTO E A REDISTRIBUIÇÃO
}

\author{
Jucélia Bispo dos Santos ${ }^{1}$
}

\section{Introdução}

No início dos anos 2000, a maioria das comunidades quilombolas baianas ainda não se reconhecia como quilombolas. Em 2004, o cineasta Antônio Olavo publicou um documentário sobre os quilombos baianos, intitulado: "Quilombos da Bahia". Esse filme aborda um pouco da trajetória de luta e da cultura das comunidades afrodescendentes daquele estado. A equipe de produção percorreu mais de 12 mil quilômetros e visitou 69 comunidades afrodescendentes para contar uma história marcada por disputas e conflitos com os grandes proprietários de terra e grileiros da Bahia. Nessas gravações, alguns sujeitos reconhecidos externamente como quilombolas não conheciam a nomenclatura quilombos. Alguns confundiam o nome quilombos com quilômetros (Olavo, 2003).

O tema dos remanescentes de quilombos promoveu a criação de novos sujeitos políticos depois da origem do Decreto 4.887/03 (BRASIL, 2004) e 20 de novembro de 2003, em todo estado da Bahia, assim como na região investigada. Essa legislação prevê o reconhecimento de quilombos através da autodeclaração coletiva do grupo. Algumas comunidades negras do Portal do Sertão da Bahia buscaram o reconhecimento oficial como comunidades quilombolas. Atualmente, existem oito comunidades quilombolas reconhecidas nessa região: Paus Altos e Gavião (Antônio Cardoso); Massaranduba, Tapera Melão, Olaria, Pedra Branca e Baixinha (Irará); Lagoa Grande (Feira de Santana); Bete II (São Gonçalo). Algumas delas foram recenseadas pela Fundação Palmares nos anos de 1990 (Tapera Melão, Olaria, e Lagoa Grande). As demais buscaram o reconhecimento inspiradas nas memórias individuais e coletivas que são narradas pelos sujeitos mais velhos que moram nesses lugares. Essa memória foi acionada depois da criação do Decreto 4.887/03, visando possibilidades de reconhecimento.

\footnotetext{
${ }^{1}$ Universidade Federal de Sergipe e Universidade do Estado da Bahia, Brasil.
} 
O movimento de construção do discurso da identidade quilombola, visando o reconhecimento e demarcação do território, começou no Portal do Sertão através da aproximação entre as prefeituras e as políticas afirmativas criadas para os quilombolas, depois da criação da SEPPIR. A Secretaria Especial de Políticas de Promoção da Igualdade Racial foi criada pelo Governo Lula no dia 21 de março de 2003. A criação dessa Secretaria partiu de uma iniciativa que se aproximava dos discursos sobre as reivindicações das comunidades quilombolas. Nessa data, o presidente Luiz Inácio Lula da Silva discursou sobre a eliminação da discriminação racial e destacou que a missão dessa secretaria especial "era de estabelecer iniciativas contra as desigualdades raciais no país" (BRASIL, 2009: 2).

As prefeituras entenderam que o primeiro passo do reconhecimento de uma comunidade quilombola parte do processo de conscientização da população sobre as atuais demandas dos quilombolas no âmbito do Estado. Vale ressaltar que, para uma comunidade ser reconhecida, qualquer integrante pode enviar um ofício para a Fundação Palmares, solicitando a presença de uma equipe no local para registrar seus dados populacionais e territoriais. Depois se faz um Relatório Técnico de Identificação e Delimitação da localidade, para ser publicado no Diário Oficial. Após esse período, a comunidade é reconhecida como sendo quilombola, com direito à propriedade da terra que historicamente lhe pertence. Delimitado o território, o grupo terá direito a sua terra. Cabe ressaltar que, estas são etapas bastante morosas, complexas e demoradas para que seja efetivamente concedido o título às comunidades quilombolas.

Esse processo gerou um engajamento de agentes internos e externos dessas comunidades. Os agentes externos estavam ligados aos movimentos sociais rurais e funcionários públicos municipais e estaduais, como: a Pastoral da Terra, mediadores políticos, representantes de ONGs, professores, agentes de saúde e estudantes universitários. Dentre os agentes internos, destacam-se os jovens que residiam nessas comunidades, os quais estão associados a grupos, como: associação de moradores rurais, movimentos estudantis universitários, Pastoral da Juventude Católica e Pastoral da Terra. Esses intermediários atuaram em diferentes campos discursivos, oferecendo embasamento para que os nativos promovessem o processo de autodeclaração enquanto quilombolas. É importante ressaltar que as fases de luta por reconhecimento dos quilombolas da região pesquisada integram um mesmo processo social de reconhecimento recíproco: primeiro ocorreu o processo aprendizagem, no qual os 
nativos aprenderam o que era ser quilombola de acordo com a legislação atual, com o apoio de atores e instituições destinados a efetivar as normas de ação livremente aceitas por meio das relações recíprocas de reconhecimento social.

Das oito comunidades quilombolas reconhecidas no Portal do Sertão da Bahia, cinco estão localizadas no município de Irará. Essas comunidades foram reconhecidas no ano de 2010, mas o processo de mobilização desses grupos começou a partir de 2007. Nesse mesmo período, os agentes políticos do município passaram a dialogar com os movimentos sociais, com o intuito de se atingir o coletivo, visando o reconhecimento das comunidades quilombolas, a garantia e a permanência das políticas sociais na esfera local. As primeiras reuniões que tratavam da questão quilombola nas comunidades iraraenses foram organizadas por mediadores externos no âmbito das ações do CRAS, da Secretaria Municipal de Educação e Cultura e das associações rurais de moradores, as quais contaram com a colaboração de representantes políticos e lideranças sindicais do município. Para a formulação dos textos nas comunidades investigadas, os atores sociais promoveram uma organização política que visava a declaração e reconhecimento dessas comunidades. Nota-se nesse procedimento que o reconhecimento da identidade não é algo estático e passa por um procedimento de produção de conhecimento e aprendizagens que constroem o reconhecimento. Como efeito, as comunidades quilombolas articularam um novo plano de resistência com fontes de identidades que foram projetadas das articulações das sociedades civis e instituições do estado de onde se originaram. Em Irará, a memória de quilombos foi estimulada a partir de 2008, com o intuito de construção da autodeclaração da comunidade como quilombola, que acontece a partir da formulação de um texto que destaque a comunidade como quilombola.

No decorrer desse processo, foram criados grupos que se organizaram em torno das reuniões de associação de moradores e das pastorais católicas. Nesse momento, os artifícios da memória e dos discursos étnicos foram utilizados em prol do reconhecimento e, assim, articularam-se o governo local e os cidadãos da comunidade. O discurso da etnia foi especificado como fonte de significado da identidade dentro de uma perspectiva de engajamento. Tais construções discursivas construíram novos códigos culturais a partir da matéria fornecida pela história. Essas construções identitárias nasceram no interior dessas comunidades e devem ser pensadas em uma perspectiva relacional, ou seja, como resultantes das relações sociais que ocorrem no 
cotidiano dos atores sociais, e não como propriedades intrínsecas compostas por uma essência imutável.

Em outras comunidades do Portal do Sertão da Bahia, o projeto de reconhecimento foi impulsionado pelos mediadores da Igreja Católica, através da Pastoral da Terra e da Pastoral de Juventude, tal como aconteceu no município de Antônio Cardoso (BA). Porém, em Irará, esse projeto foi engendrado por pessoas vinculadas aos movimentos sociais locais, intelectuais, professores da rede municipal, profissionais do CRAS (Centro de Referência da Assistência Social), representantes de partidos políticos, e outros. Os mediadores que mais se destacaram foram as lideranças políticas do Partido dos Trabalhadores (PT) e os professores da Educação Básica. Os profissionais da educação entenderam que a temática dos quilombos era um tema importante para ser trabalhado na sala de aula, sobretudo nas aulas de História que tinham com objetivo a implementação da lei 10639/03(Brasil, 2006), cuja proposta é o ensino de História da África e da Cultura Afro-brasileira.

Esse artigo objetiva analisar a trajetória política do movimento dos quilombolas da comunidade de Olaria, em Irará (BA), a fim de entender como os mediadores supracitados construíram o discurso de quilombola na região pesquisada. Na sequência, destaca-se como ocorreu o reconhecimento dessa comunidade e implementação das políticas sociais para quilombolas.

\section{Imersão no Campo de Pesquisa}

A minha aproximação da comunidade de Olaria ocorreu em dois momentos: primeiro, em 2006, na ocasião da experiência do mestrado; segundo, entre 2010 e 2012, na experiência da pesquisa do doutorado. Nesse período, ocorreu o envolvimento de sujeitos políticos diferenciados nessa comunidade, à medida que o termo quilombola ganhava novos sentidos: a princípio, o conceito estava associado à ideia de desconhecimento. Depois ganhou um contorno na mobilização política, a fim de forjar uma identidade quilombola segundo o critério da autoatribuição. Por fim, o uso do termo foi articulado com o processo de reconhecimento, com o foco voltado para a luta por redistribuição de políticas para as comunidades quilombolas. 
A partir de 2010, voltei para a comunidade pesquisada para coletar dados da pesquisa de Doutorado. Nesse trabalho de campo, participei de diversas reuniões como observadora e como sujeito social, acompanhando as comunidades quilombolas de Irará e de outros municípios do Portal do Sertão. Nessas reuniões eram discutidos e traçados planos políticos que redefiniam a relação dessas comunidades com os agenciamentos discursivos que incentivavam a mobilização da identidade quilombola e a busca do reconhecimento.

Durante a experiência etnográfica, que foi produzida durante a pesquisa de mestrado, entre 2006 e 2007, notei que no início, sobretudo em 2006, várias das pessoas que residem nesses espaços, designados externamente como "remanescentes dos quilombos" ainda não se reconheciam como quilombolas, bem como também não relacionavam o seu passado com a nomenclatura clássica de quilombos (Santos, 2008). Constatei na experiência em campo, que alguns nativos habitantes dessas localidades ainda não visualizavam a possibilidade de utilização da identidade quilombola fomentada por meio da Constituição de 1988. Essa Constituição determina, através do Artigo 68 do Ato das Disposições Transitórias o reconhecimento e a titulação das chamadas, "terras remanescentes de quilombos". Conclui, ao final da pesquisa, em 2008, que já existia uma mobilização nessas comunidades, com o de criar bases ideológicas necessárias para se fomentar coletivamente a afirmação da identidade quilombola por meio da certificação publicada no Diário Oficial da União.

Quando entrei em contato com a comunidade, em 2010, os moradores já haviam decidido acionar o Artigo 68 mais o Decreto $n^{\circ} 4887 / 2003$ como uma forma de assegurar as terras que habitavam e outras políticas públicas destinadas aos quilombolas. Observei que já existia na comunidade de Olaria a construção de um novo discurso em torno do reconhecimento e redistribuição das comunidades quilombolas. Vi que os sujeitos envolvidos nesse processo manipularam os termos supracitados dentro de um composto discursivo que objetivava a correção das desigualdades e a valorização da cultura afro-brasileira.

Nas primeiras entrevistas, percebi que a comunidade de Olaria era beneficiada por algumas políticas públicas destinadas para quilombolas. Aproximei-me do Centro de Referência de Assistência Social do município, qual já possuía uma denominação de CRAS quilombola, com objetivo de consultar documentos e entrevistar os profissionais 
que atuavam nesse órgão. De acordo com a ata de fundação do CRAS ${ }^{2}$, essas políticas foram criadas entre 2003 e 2013, a partir dos projetos criados em torno dos governos Lula e da presidente Dilma Rousseff, os quais fomentaram o discurso de governo democrático e popular. Esses planos de governo criaram um discurso voltado para a criação de políticas para o enfrentamento da pobreza e da exclusão social. No seu primeiro discurso como presidenta do Brasil, a petista Dilma Rousseff afirmou que daria continuidade ao projeto de combate às desigualdades iniciado pelo seu companheiro de partido, o ex-presidente Lula, e "a luta mais obstinada" de seu governo seria a erradicação da miséria no país ${ }^{3}$. Diversas ações governamentais foram criadas na perspectiva de efetivar a propagação desses discursos nos espaços regionais a partir das políticas criadas pelos diversos ministérios.

Os programas redistributivos do governo foram criados paralelamente aos programas voltados para o reconhecimento dos direitos culturais e das identidades. A partir de 2003, o governo do PT criou programas de implementação de políticas públicas, como o Fome Zero, o Bolsa Família e o Brasil Quilombola, com base no discurso da promoção da justiça social. Esses programas tinham como objetivos promover a inclusão/autonomia dos indivíduos através das políticas afirmativas no ideário liberal. Essas políticas de reconhecimento legitimam os discursos da inclusão e da diversidade, e assim contemplam a teoria de Fraser (2006) sobre o reconhecimento através da aproximação do conceito de status social: não ser reconhecido significa estar subordinado socialmente. Sendo assim, a subordinação se expressa na forma como a injustiça priva certos grupos de participarem igualmente da vida social.

Depois do governo Lula, a vulnerabilidade dessas comunidades passou a ser vista através do discurso de classe e raça, transversalmente à introdução de mudanças mais substantivas na condução das políticas de cunho racial por meio da criação da secretaria dedicada à promoção da igualdade racial. Assim, o Estado reconheceu que era preciso rever as desigualdades sociais que foram promovidas a partir da ideia de status, fundamentada na concepção de classe é raça. Segundo Edward Telles (2003) em seu livro Racismo à brasileira, no Brasil existe grande desigualdade, desvantagem para os não brancos que não são apenas materiais, mas uma inferioridade social que pode ser

\footnotetext{
${ }^{2}$ Prefeitura Municipal de Irará. Secretaria de Desenvolvimento Social. Ata de fundação do CRAS Quilombola, março de 2008.

${ }^{3}$ http://www.brasil.gov.br/governo/2011/01/-do-discurso-de-posse-de-dilma-rousseff-no-congresso. Visitado em 23/09/2013.
} 
traduzida em uma cidadania aleijada que encontra obstáculos como o acesso ao emprego e aos direitos civis e políticos, envolvendo também diferença de poder e status.

O discurso do reconhecimento articulado em torno dos governos do PT promoveu a criação de políticas que tentam reparar as injustiças de status dos membros da sociedade. Contudo, cabe ressaltar que o reconhecimento não se apresenta necessariamente ligado à categoria de exploração, verdadeira matriz da desigualdade social. Porém, ele não se dissocia das questões econômicas e produtivas, uma vez que estabelece como prioridade as políticas de reconhecimento de status por meio de um projeto que objetiva promover a correção de injustiças sociais. As políticas afirmativas do governo Lula afetam outros grupos não reconhecidos além dos negros, sobretudo aqueles trabalhadores desqualificados e que se inserem de forma "subalterna, invisível, reificada" - nos termos usados por Honneth (2008: 157) para se referir à experiência de não reconhecimento e mão de obra mal valorizada no mundo do trabalho.

$\mathrm{Na}$ estruturação do Governo Lula, a SEPPIR foi incumbida de desenvolver o planejamento, execução e acompanhamento dos investimentos sociais do Governo Federal nas comunidades quilombolas certificadas pela Fundação Cultural Palmares. E daí promover a formulação de políticas voltadas para a garantia dos direitos territoriais e aquelas dedicadas ao etnodesenvolvimento, sobretudo aquelas pensadas para os povos tradicionais, criaram novas políticas para as populações quilombolas no âmbito do governo federal. As primeiras políticas foram fomentadas no programa intergovernamental Brasil Quilombola, assim como a constituição da Secretaria Especial de Promoção da Igualdade Racial, que é responsável pela coordenação desta política.

Para melhor entender a redistribuição de políticas públicas para quilombolas na comunidade da Olaria, consultei alguns documentos do CRAS que abordavam a temática. Encontrei nesse arquivo alguns manuais que trata da organização do Programa Brasil Quilombola (PBQ). Esse programa foi criado no início da criação da SEPPIR. Entre 2003 e 20013, o PBQ divulgou relatórios anuais que tratam da análise das políticas quilombolas no Brasil. A partir dessa documentação, observei que a SEPPIR contratou como gestoras pessoas que tinham vínculos diretos com os movimentos sociais; o que aproximava os discursos políticos dos discursos dos militantes. Desse modo, a SEPPIR era responsável pela construção do Plano Nacional de Promoção da Igualdade Racial, que surgiu através de uma deliberação da I Conferência Nacional de 
Promoção da Igualdade Racial. ${ }^{4}$ Por meio do PBQ, a SEPPIR intenciona garantir a implantação das políticas das comunidades quilombolas. Nos relatórios anuais do PBQ (sobretudo nos de 2006, 2007, 2008 e 2009), a SEPPIR faz um balanço dos principais projetos que foram implantados em diversas comunidades quilombolas do território brasileiro.

Essa nova secretaria nasceu com o objetivo de efetivar os discursos do reconhecimento e da redistribuição previstos na Constituição de 1988, nos Artigos 68 da ADCT e 215 e 216 da Constituição, assim como o Decreto 4.877/2003. Esse novo conceito de identidade quilombola aproxima as comunidades do discurso do estado de bem-estar social, o qual visa assegurar os direitos civis e políticos, que são os direitos de $1^{\text {a }}$ dimensão, tratando das liberdades individuais ${ }^{5}$, como também implantação de novas políticas sociais voltadas para o povo, com o intuito de garantir direitos econômicos, sociais, culturais e ambientais.

\begin{tabular}{|l|l|}
\hline Acesso à terra & Certificação e regularização fundiária \\
\hline Infraestrutura e qualidade de vida & $\begin{array}{l}\text { PAC Funasa; A Funasa, como integrante } \\
\text { do componente de infraestrutura social e } \\
\text { urbana do Programa de Aceleração do } \\
\text { Crescimento (PAC), atuou no período de } \\
2007 \text { a 2010, em articulação com os } \\
\text { Ministérios das Cidades e da Integração } \\
\text { Nacional. Programa água para todos; } \\
\text { Programa Nacional de Habitação Rural; } \\
\text { Programa Luz para Todos; Tarifa Social. }\end{array}$ \\
\hline Desenvolvimento Local e Inclusão & $\begin{array}{l}\text { Declaração de Aptidão ao Pronaf - Dap; } \\
\text { Programa Cisternas; Segurança Alimentar } \\
\text { e Nutricional; Programa De Aquisição De } \\
\text { Alimentos - PAA; Assistência Técnica e }\end{array}$ \\
\hline
\end{tabular}

\footnotetext{
${ }^{4}$ I Conferência Nacional de Promoção da Igualdade Racial: Brasília, 30 de junho a 2 de julho de 2005: Relatório Final/ Secretaria Especial de Políticas de Promoção da Igualdade Racial, Conselho Nacional de Promoção da Igualdade Racial. - Brasília: Secretaria Especial de Políticas de Promoção da Igualdade Racial, 2005.

${ }^{5}$ Direito de ir e vir, liberdade de expressão, devido processo legal, direito de defesa, liberdade de religião, direito à associação. IVO, A. L. A "destituição" do social: Estado, governo e políticas sociais, Caderno CRH, Salvador, n. 35, p. 41-84, jul./dez. 2001.
} 


\begin{tabular}{|l|l|}
\hline Direitos e Cidadania & $\begin{array}{l}\text { Inclusão Rural; Quilombola - ATER; Selo } \\
\text { Quilombos do Brasil; Programa Brasil } \\
\text { Local - Economia Solidária. }\end{array}$ \\
\hline $\begin{array}{l}\text { Programa Nacional de Educação do } \\
\text { Campo; Programa Nacional do Livro } \\
\text { Didático - PNLD; Programa Dinheiro } \\
\text { Direito na Escola - PDDE; Procampo; } \\
\text { Educação Quilombola; Programa } \\
\text { Nacional de Alimentação; Escolar - } \\
\text { PNAE; Programa Nacional De Acesso ao } \\
\text { Ensino Técnico e Emprego - } \quad \\
\text { PRONATEC; Programa Bolsa Família - } \\
\text { PBF; Busca Ativa - Cadúnico; Programa } \\
\text { Saúde Da Família - PSF; Programa Saúde } \\
\text { Bucal- PSB; Telecentro - Br; Rádios } \\
\text { Comunitárias; Documentação Básica E } \\
\text { Registro Civil }\end{array}$ \\
\hline
\end{tabular}

Quadro 1: Principais políticas para quilombolas no Brasil atual. Programa Brasil Quilombola. Diagnóstico de Ações Realizadas, Brasília, SEPPIR, Julho de 2012.

As políticas das comunidades quilombolas estão inseridas no contexto do discurso da efetividade dos direitos econômicos, sociais e culturais. Em torno da nova política social existe uma perspectiva de garantir direitos conferidos na Constituição Federal, como: direito à saúde, à educação, à segurança, à aposentadoria, à moradia, proteção à infância, ao idoso, à maternidade e programas sociais (BRASIL, 2004). Esses direitos se aproximam de uma meta proporcionada pelo Estado do bem-estar, não se restringindo apenas em efetivar os direitos de primeira e segunda geração. Mas também interferindo na economia, agindo como empresário em áreas que o setor privado jamais investiria. São direitos que buscam equilíbrio, para erradicar a miséria, a pobreza e toda forma de discriminação; apoiam o progresso e ao mesmo tempo preserva o meio ambiente, protegendo a propriedade, desde que priorizada sua função social. 
As novas políticas criadas no âmbito da SEPPIR aproximaram os quilombolas das garantias individuais e sociais (BRASIL, 2007). Essas políticas estavam associadas aos discursos que tentavam criar uma imagem de governo democrático, justo e legítimo, através da ampla participação da população em suas instâncias representativas; ele tem como característica discursiva o pluralismo político e, por objetivo, a construção de uma sociedade justa e solidária, sem preconceito de cor, raça, religião e sexo, abolindo todas as formas de discriminação, segundo os artigos $1^{\circ}$ e $3^{\circ}$, da Constituição Federal (Leite, 2000). Vale destacar que o ponto de partida que impulsionou a busca do processo de emissão de certificação de comunidades também foi incentivado com as políticas sociais adotadas no governo Lula:

Desde 2003, com a criação da Secretaria Especial de Políticas de Promoção da Igualdade Racial - SEPPIR, o Governo Federal fundamenta os princípios da política que orientam a sua ação para as comunidades quilombolas, dando-lhe maior objetividade na busca de superação dos entraves jurídicos, orçamentários e operacionais, que impediam a plena realização dos seus objetivos. O Programa Brasil Quilombola, criado em 2004, tem como finalidade essencial a coordenação das ações governamentais - articulações transversais, setoriais e interinstitucionais - para as comunidades remanescentes de quilombos, com ênfase na participação da sociedade civil. O Programa é coordenado pela SEPPIR, por meio da Subsecretaria de Políticas para Comunidades Tradicionais, e tem suas ações executadas por 21 órgãos da administração pública federal, além de empresas e organizações sociais (BRASIL, 2012: 2).

Com a implantação de políticas sociais para quilombolas, o referido governo passou a aplicar programas redistributivos de caráter universalista, como o Fome Zero e o Bolsa Família ${ }^{6}$. Esses programas possuem a estratégia da transferência direta de renda com condicionalidades, e tem como objetivo combater a fome, a pobreza e outras formas de privação das famílias. Nesses novos programas sociais, os quilombolas foram contemplados com políticas voltadas à educação, infraestrutura, habitação, saúde, crédito agrícola, dentre outros. Tais programas estão associados a uma política social de transferência de renda, a qual tem como objetivo diminuir os efeitos da pobreza nos territórios com vulnerabilidade social e, assim, contribuir para a conquista da cidadania.

\footnotetext{
${ }^{6}$ Este programa foi criado pela Lei $n^{\circ} 10.836 / 2004$ e regulamentado pelo Decreto 5.209/2004, onde estabelece as condicionalidades do programa como compromisso do poder público e das famílias atendidas. Ministério do Desenvolvimento Social e Combate à Fome. Bolsa Família: cidadania e dignidade para milhões de brasileiros. Brasília: MDS, 2010.
} 
Por meio do PBQ, a SEPPIR visa garantir a implantação das políticas das comunidades quilombolas. Os relatórios anuais do PBQ apontam que nos anos dos de 2006, 2007, 2008 e 2009, a criação da SEPPIR mobilizou a instalação de novas políticas públicas em diversas comunidades quilombolas do território brasileiro. Cabe ressaltar que esse movimento está relacionado com o processo de municipalização das políticas públicas que iniciadas a partir da Constituição de 1988. A nova constituição efetivou a transferência das políticas para os municípios, as quais eram tradicionalmente coordenadas e/ou executadas pelos governos federal e estaduais. Essa municipalização está associada ao discurso de democratização da sociedade brasileira e tem sido estimulada pelos organismos internacionais que financiam e apoiam países em desenvolvimento, como: UNESCO e o Banco Mundial (Arretche, 1999).

A criação do CRAS quilombola se justifica no contexto dessas ações promovidas pelo governo federal nos últimos dez anos. Depois da criação de políticas sociais das comunidades quilombolas, as prefeituras entenderam que era possível buscar mais recursos para os municípios através da temática dos quilombolas.

Entrevistei os profissionais do CRAS para tentar entender quais eram os principais objetivos desse órgão no município de Irará. De acordo com o psicólogo $\mathrm{WC}^{7}$ :

O CRAS quilombola foi criado, em Irará, a partir das políticas do PAIF (Programa de Atenção Integral à Família). Essa política objetiva atingir as populações vulneráveis, como: povos indígenas, quilombolas e comunidades rurais. No munícipio de Irará, o programa foi implementado nas comunidades quilombolas. A princípio, os quilombolas não sabiam que eram quilombolas. Esse projeto chegou município a partir do ano de 2004, quando o antigo prefeito Amaro Bispo dos Santos, encaminhou um projeto criado por consultores externos para Ministério do Desenvolvimento Social. Esses consultores trabalham com editais que são publicados pelo governo federal. Eles constroem os projetos de acordo com a disponibilidade de recursos. Nesse momento esses recursos eram destinados para as comunidades quilombolas. Dessa forma, eles buscaram o censo da Fundação Palmares para mapear as principais comunidades quilombolas da Bahia. Como Irará possuía comunidades quilombolas recenseadas, suponho que eles procuraram o prefeito para vender o projeto. Digo vender, porque

\footnotetext{
${ }^{7}$ O referido psicólogo trabalhou no CRAS de Irará e participou do processo de fundação. Essa entrevista foi concedida em 28/09/2012.
} 
quando o projeto é aprovado, assim como foi, a consultoria recebe $5 \%$ do valor do projeto.

O CRAS quilombola foi criado no município de Irará a partir da articulação da Prefeitura, com as novas políticas para as comunidades quilombolas, que foram criadas no Ministério de Desenvolvimento Social (MDS). De acordo com a entrevista, essa política não foi reivindicada pelos quilombolas; até porque os mesmos ainda não compreendiam o que era ser quilombola no contexto do Brasil contemporâneo. Percebi que esse processo foi utilizado como mais uma estratégia de aplicação de recursos federais no município.

O primeiro programa voltado para as comunidades quilombolas implantado no município foi o Programa de Atenção Integral à Família (PAIF) ${ }^{8}$. Através do PAIF, o Sistema Único de Assistência Social (SUAS) visava atender uma população que vivia em situação de vulnerabilidade social decorrente da pobreza, privação e/ou fragilização de vínculos afetivos de pertencimento social (discriminações etárias, étnicas, de gênero ou por deficiências, dentre outras). Vale destacar que esse programa foi criado em 18 de abril de 2004 (Portaria no 78), pelo Ministério do Desenvolvimento Social e Combate à Fome - MDS, o qual tinha os seguintes propósitos de funcionamento (BRASIL, 2006, 98): Promover a recepção e acolhida das famílias, seus membros e indivíduos em situação de vulnerabilidade social; Ofertar procedimentos profissionais em defesa dos direitos humanos e sociais e dos relacionados às demandas de proteção social de Assistência Social; Atuar na vigilância social, na produção e na sistematização de informações que possibilitem a construção de indicadores e de índices territorializados das situações de vulnerabilidades e riscos que incidem sobre famílias/pessoas nos diferentes ciclos de vida. Promover o reconhecimento das famílias referenciadas e as beneficiárias do Benefício de Prestação Continuada (BPC) e do Programa Bolsa Família (PBF); Desenvolver o acompanhamento familiar: em grupos de convivência, reflexão e serviço socioeducativo para famílias ou seus representantes; dos beneficiários do PBF, em especial das famílias que não estejam cumprindo as condicionalidades; das famílias com beneficiários do BPC; Aplicar a proteção pró-ativa por meio de visitas às famílias que estejam em situações de maior risco ou vulnerabilidade (como, por exemplo, as famílias que não estão cumprindo as condicionalidades do PBF); Implantar o encaminhamento para avaliação e inserção dos potenciais beneficiários do PBF no

\footnotetext{
${ }^{8}$ BRASIL. Secretaria Especial de Políticas de Promoção Da Igualdade Racial. Subsecretaria de Políticas para Comunidades Tradicionais, Relatório, p 26, 2006, Brasília.
} 
Cadastro Único (CadÚnico) e do BPC, na avaliação social e do INSS; das famílias e indivíduos para a aquisição dos documentos civis fundamentais para o exercício da cidadania; encaminhamento (com acompanhamento) da população referenciada no território do CRAS para serviços de proteção social básica e de proteção social especial - quando for o caso; Atuar na produção e divulgação de informações de modo a oferecer referências para as famílias e indivíduos sobre os programas, projetos e serviços socioassistenciais do SUAS, sobre o PBF e o BPC, sobre os órgãos de defesa de direitos e demais serviços públicos de âmbito local, municipal, do Distrito Federal, regional, da área metropolitana e ou da micro-região do estado; Apoiar nas avaliações de revisão dos cadastros do PBF e do BPC e demais benefícios.

O projeto do PAIF foi inserido nos municípios do Brasil depois do governo Lula, que criou um novo projeto para implementação das políticas sociais, que, após passar por um processo de reformas, promoveram novas relações entre os sujeitos de direito e a gestão da política social. Essa mudança motivada pelo discurso pretendeu provocar a otimização de recursos passados para os municípios e assim criar condição para maior eficiência e, consequentemente, maior agilidade e transparência na prestação de serviços públicos pelo Estado. Além disso, esse novo modelo de gestão pretendia promover maior envolvimento dos agentes locais no contexto da promoção da educação, através do controle de gastos e na inspeção do cumprimento das metas estabelecidas e, a um só tempo, o acompanhamento dessas ações pelo setor público.

O PAIF contava em sua composição básica no quadro técnico os seguintes profissionais: assistentes sociais e psicólogos, os quais desenvolviam as seguintes funções em torno do projeto:

Funções da Equipe Técnica do PAIF

$1^{\text {a: }}$ Recepção e acolhida das famílias, seus membros e indivíduos em situação de vulnerabilidade social;

$2^{\mathrm{a}}$ : Oferta de procedimentos profissionais em defesa dos diretos humanos e sociais e dos relacionados às demandas de proteção social de Assistência Social;

$3^{a}$ Divulgação de informações que possibilitem a construção de indicadores e de índices terrritorializados das situações de vulnerabilidades e riscos que incidem sobre famílias/pessoas nos diferentes ciclos de vida.

$4^{\mathrm{a}}$ Acompanhamento Familiar, através em grupos de convivência, reflexão e serviço 
socioeducativo para famílias ou seus representantes;

$5^{\mathrm{a}}$ Proteção proativa por meio de visitas às famílias que estejam em situações de maior risco ou vulnerabilidade;

$6^{\mathrm{a}}$ Encaminhamentos: para avaliação e inserção dos potenciais beneficiários dos serviços de proteção social básica de proteção social especial;

$7^{a}$ Produção e divulgação de informações de modo a oferecer referências para as famílias e indivíduos sobre os programas, projetos e serviços socioassistenciais do SUAS, sobre o PBF e o BPC, sobre os órgão de defesa de direitos e demais serviços públicos de âmbito local, municipal, do Distrito Federal, regional, da área metropolitana e ou microrregião do estado;

Quadro 2: Ações desenvolvidas em torno do PAIF Fonte: http://www.mds.gov.br/programas/redesuas/protecao-social-basica/paif, consultado, em 12/08/2012)

O PAIF foi criado no município de Irará para assistir as comunidades quilombolas recenseadas pela Fundação Palmares. Assim sendo, foram implementadas as primeiras ações e serviços básicos continuados para famílias em situação de vulnerabilidade social na unidade do CRAS desse município. Com esse projeto, pretendia-se promover uma articulação focada para a melhoria das condições de vida dos quilombolas que, historicamente, encontravam-se à margem do acesso à terra, educação, saúde, emprego, saúde, cultura. Assim, o PAIF passou a atender 1739 comunidades quilombolas, localizadas em 330 municípios de 22 estados brasileiros (BRASIL, 2006: 58).

No município Irará, a equipe do PAIF foi responsável pela divulgação dos direitos e das políticas voltadas para os quilombolas nas comunidades. Esses agentes que trabalharam na equipe do PAIF levaram para comunidades um discurso sobre os direitos quilombolas, até então desconhecido por várias pessoas das comunidades. Dessa forma, os quilombolas do Portal do Sertão da Bahia passaram a conhecer novos conceitos que estavam associados aos direitos quilombolas, como: identidade, reconhecimento e territorialidade.

Quando o discurso da identidade quilombola surgiu na comunidade da Olaria, estava relacionado com a exclusão social e num projeto de implementação de políticas sociais para quilombolas que foi desenvolvido em torno do CRAS (Centro de Referência de Assistência Social) e da Secretaria de Desenvolvimento Social do 
município. Os agentes municipais articularam o discurso da identidade e do reconhecimento de quilombolas com o discurso de justiça social. De acordo com Barzotto (2003), o bem da justiça social é o "bem comum" e a atividade própria da justiça social é o "reconhecimento", uma prática complexa. Dessa forma, compreende se que o reconhecimento é uma prática de considerar o outro como sujeito de direito ou pessoa, como um ser que é "fim em si mesmo" e que possui uma dignidade que é fundada em direitos e deveres. Aqui a concepção de reconhecimento aproxima da ideia de Fraser (2001), quando atesta que as identidades substituem interesses de classe como principal incentivo para mobilização política no século XX.

\section{Engajamento político e empoderamento de lideranças}

Quando o discurso da identidade quilombola surgiu na comunidade da Olaria, estava relacionado com a exclusão social e num projeto de implementação de políticas sociais para quilombolas que foi desenvolvido em torno do CRAS (Centro de Referência de Assistência Social) e da Secretaria de Desenvolvimento Social de Irará.

A SEDESO se aproximou dessa comunidade através de projetos que estabeleciam conexões com as políticas públicas federais criadas para os quilombolas, como o PAIF. Os profissionais que faziam parte da equipe do PAIF participaram de cursos de formação e nesses cursos eles entenderam que, para o município de Irará implementar outros programas de assistência social, seria preciso que as comunidades quilombolas obtivessem o reconhecimento jurídico de acordo o Decreto $\mathrm{n}^{\mathrm{o}}$ 4.887/032(BRASIL, 2012), o qual determinava que o reconhecimento das comunidades seria ajustado conforme o critério da autoidentificação.

Nesse período, o poder público mobilizou algumas secretarias para que promovessem o projeto do reconhecimento jurídico da comunidade da Olaria e de outras que estavam inseridas na assistência do PAIF, como: Baixinha, Pedra Branca, Crioulo e Largo. Conforme narra a seguinte entrevistada ${ }^{9}$ :

No período que trabalhei no CRAS, descobrimos que existiam políticas federais voltadas para as comunidades quilombolas. Várias dessas comunidades já eram assistidas através do PAIF, porém esse programa não dava conta das principais demandas dessas comunidades. Percebíamos que essas comunidades precisavam de

\footnotetext{
${ }^{9}$ IC: assistente social do município de Irará. Entrevista concedida em 28/09/2012. Grupo focal 05.
} 
políticas mais efetivas, como: habitação, luz elétrica, água encanada, aquisição de alimento, saúde e outras. Foi aí que pesquisamos e entendemos que o projeto do reconhecimento era o caminho inicial da mudança dessas comunidades, uma vez que os ministérios, como o MDS, exigem o reconhecimento dessas comunidades para as mesmas serem inseridas em programas destinados aos quilombolas.

Nessa fase os agentes municipais articularam o discurso da identidade e do reconhecimento de quilombolas com o discurso de justiça social. Os mediadores que atuaram no processo de construção do projeto do reconhecimento das comunidades quilombolas de Irará compreendiam que o processo de reconhecimento das comunidades quilombolas deveria começar através da manifestação da própria comunidade quilombola, conforme a previsão do Decreto 4.887/2003. Essa mobilização atingiu outras comunidades do município que não foram recenseadas pela Fundação Palmares, como Pedra Branca, Massaranduba e Baixinha.

Além dos mediadores vinculados à prefeitura, outros mobilizadores, vinculados aos movimentos sociais rurais, se aproximaram dos moradores da Olaria. A partir do ano de 2008, os dirigentes da associação rural (Evandro Silva Vieira e Joemia Xavier) estabeleceram uma aproximação do sindicato rural de Irará e de outros políticos ligados ao PT (Partido dos Trabalhadores). Os mediadores dessas instituições supracitadas participaram ativamente da fomentação do discurso de autorreconhecimento de quilombola. A partir desse diálogo, a associação rural da Olaria, fundada em 1997, inseriu em suas reuniões o debate sobre o processo de reconhecimento de quilombolas. As reuniões que ocorreram mensalmente e nos encontros, eles discutem questões pertinentes à dinâmica da vida local e falavam sobre possibilidades de mudanças na comunidade. De acordo com a entrevistada: As primeiras reuniões que falavam sobre a questão do quilombola ocorreram a partir de 2008. Nessa ocasião, a associação se aproximou do sindicato rural e lá descobrimos que existiam várias políticas para as comunidades quilombolas. Aqui já existia o PAIF, mas descobrimos que era possível buscar mais recursos para a nossa comunidade. Assim, começamos nos reunir, aos domingos, para discutir para ideia do reconhecimento. Contamos com o apoio de várias pessoas do município e de fora. Essas pessoas trabalham na Prefeitura Municipal e outras estão ligadas politicamente ao sindicato. 
No dia 15 de julho de 2008, aconteceu uma audiência pública na comunidade de Olaria que contou com a organização da assessoria do gabinete do Deputado Estadual José Cerqueira de Santana Neto (PT, BA). O referido deputado tem uma trajetória política vinculada aos movimentos sociais. A sua história começou na luta do movimento estudantil nos anos de 1980, quando o mesmo era estudante de Direito da Universidade Federal da Bahia. No ano 2000, Zé Neto conquistou espaço na Câmara de Vereadores de Feira de Santana (BA), o que o tornou o primeiro vereador pelo Partido dos Trabalhadores (PT) no município. Em 2006 e 2010, ele foi eleito deputado estadual $^{10}$. Nas ações de seu gabinete existem projetos voltados para diversas demandas de movimentos sociais, como: movimento dos trabalhadores rurais, movimento negro, movimento sindical de professores e outros. A partir das ações do gabinete, o deputado se aproximou das lideranças das comunidades rurais e agiu como mediador do debate do reconhecimento das comunidades quilombolas do Portal do Sertão da Bahia, dentre elas, a comunidade de Olaria.

A audiência pública do processo de reconhecimento contou com a presença de outros políticos do município de Irará, como: o então prefeito Derivaldo Pinto (PT, BA), o vereador Ubiratan da Silva Reis (PCdoB, BA), Fabiana Marques (PT, BA, representantes do sindicato dos professores); Josafá Ferreira (PT, BA, representante do sindicato dos trabalhadores) e representantes das comunidades quilombolas de Irará, Evandro (presidente da associação rural das comunidades de Olaria e Pedra Branca), Djalma (presidente da Associação Rural da Comunidade de Tapera Melão) e Edivan (presidente da Associação Rural da Comunidade da Baixinha). Nessa reunião, os já citados mediadores políticos falaram sobre o atual conceito de quilombo adotado na legislação brasileira e sobre a necessidade das comunidades construírem um texto de autodeclaração como comunidade quilombola ${ }^{11}$.

De acordo com a fala do Deputado José Neto, o reconhecimento dessas comunidades promoveria um processo de inclusão social para os seus moradores, uma vez que o Governo Federal criara algumas políticas sociais para as comunidades quilombolas. Os agentes da política local também ressaltaram a importância do reconhecimento dessas comunidades. O prefeito demonstrava interesse no processo de reconhecimento e afirmou: “o reconhecimento dessas comunidades poderá garantir mais

\footnotetext{
${ }^{10}$ http://www.zeneto.com.br/conheca-ze-neto.php, consultado em 02/02/2014.

${ }^{11}$ Ata da Associação dos Moradores da Olaria e Pedra Branca. Reunião que teve como pauta a construção do documento de autodeclaração, enquanto quilombola, realizada no dia 15 de julho 2008.
} 
verbas para o município." Existia nessa plenária um consenso quanto à necessidade do reconhecimento das comunidades quilombolas de Irará, e isso conduziu outras comunidades que não haviam sido recenseadas como quilombolas. De acordo com o censo da Fundação Palmares, apenas as comunidades de Crioulo, Olaria e Tapera eram consideradas como remanescentes de quilombos. Mas, depois das reuniões que eram promovidas visando à busca do processo de reconhecimento das comunidades quilombolas, outras comunidades, como as de Baixinha, Pedra Branca e Massaranduba também se aproximaram da luta pelo reconhecimento como quilombolas, uma vez que se reconhecem como descendentes de escravos e viverem num processo de exclusão social e da propriedade da terra, assim como as comunidades que foram recenseadas pela Fundação Palmares.

A construção do projeto das comunidades quilombolas de Irará promoveu um amplo debate sobre as questões que enfatizam a justiça social e a correção da pobreza. De acordo com os discursos proferidos na reunião, a falta de acesso aos bens de consumo e a condição de pobreza eram as principais característica do grupo. $\mathrm{O}$ presidente da Associação Rural dos Moradores da Baixinha, Edivan dos Santos ${ }^{12}$, destacou o seguinte:

Eu moro na comunidade da Baixinha. Nós somos uma comunidade pobre, isso não nos envergonha, mas a nossa condição de pobreza deveria envergonhar os políticos, porque lá falta tudo. Teve um estudo feito por uns estudantes da Universidade Estadual de Feira de Santana que destacou a nossa comunidade como uma favela rural. Nenhuma comunidade rural de Irará já recebeu esse nome. Isso mostra o quanto nós precisamos de apoio.

Nesse discurso, o orador deixa clara a condição de invisibilidade de sua comunidade e a necessidade da intervenção do Estado. Percebe-se que essa comunidade enfrentou a exclusão social dos sujeitos que está associada à privação, falta de recursos, ou, de uma forma mais abrangente, ausência de cidadania, quanto à participação plena na sociedade, nos diferentes níveis em que esta se organiza e se exprime: ambiental, cultural, econômico, político e social. A falta de acesso às oportunidades oferecidas pela sociedade aos sujeitos quilombolas acarretou o aparecimento de zonas de pobreza, antes restritas a bolsões determinados, trazendo ao setor público desafios quase intransponíveis. O uso do discurso sobre a exclusão social já fazia parte de trajetória da

\footnotetext{
${ }^{12}$ Depoimento de Edivan dos Santos: professor e estudante de Licenciatura de Educação do Campo da UFRB/ Feira de Santana. Ata da associação dos moradores da Olaria: 15/07/2008.
} 
comunidade da Olaria bem antes da expectativa do reconhecimento. Um jornal de circulação mensal, A Gazeta de Irará, publicou, em abril de 2002, um texto que aponta o nível da pobreza da região pesquisada ${ }^{13}$ :

As localidades do Periquito e Olaria são, com certeza, as comunidades mais carentes do município de Irará, e precisam de ajuda do governo municipal, Igreja Católica, Igreja Evangélica e toda a comunidade iraraense, no sentido de amenizarmos a pobreza absoluta. Vivem todos (ou a sua maioria) abaixo da linha de pobreza. Numa verdadeira chaga social. Casas de chão batido. Ajudem! Precisamos unir forças para encontrarmos uma forma de ajudar. Pois da forma que está não pode continuar. É preciso um trabalho de conscientização de planejamento familiar (pois existem adolescentes se tornando mães solteiras), casais desajustados, alcoolismo. Mas, com a orientação de entidades, podem sair deste abismo, em médio ou em longo prazo. Você que tem condições, melhor! Pode ajudar as famílias carentes de Olaria.

A partir de informações do jornal local, observa-se que essas pessoas possuem um perfil de extrema pobreza. Isto inclui não apenas os aspectos econômicos associados à insuficiência da renda corrente dos indivíduos ou famílias, mas também às condições de acessibilidade aos serviços da infraestrutura social, as oportunidades de ascensão social, a participação política, dentre outros. Esse fenômeno de exclusão foi tratado, durante vários anos, no Brasil, na esfera do planejamento público, sustentado pelo discurso de "vulnerabilidade social", vinculado às circunstâncias de extrema pobreza e degradação humana.

No caso da comunidade de Olaria, as pessoas construíram uma trajetória marcada pela pobreza, a qual é percebida como carência ou falta de meios para suprir as necessidades básicas. Tal fato apresenta-se tanto em sua forma mais acentuada de pobreza absoluta, também chamada de miséria ou indigência, em que o mínimo imprescindível para a sobrevivência física não é assegurado, basicamente a alimentação; como em sua forma menos acentuada, em que os indivíduos não têm acesso ou esse, ainda que exista, é precário em relação a outros bens e serviços de grande importância para uma vida saudável, como: vestuário, transporte, habitação, saúde, educação e lazer. O não reconhecimento desses grupos está associado a uma especificidade etnico-racial e territorial.

\footnotetext{
${ }^{13}$ A Gazeta de Irará: Abril de 2002-Ano III-n॰19, pág.03.
} 
A vulnerabilidade da comunidade da Olaria pode ser compreendida em três dimensões: a primeira relaciona à vulnerabilidade social, à ausência ou escassez de renda das famílias ou dos indivíduos, por conta da falta de inserção dos sujeitos no mercado de trabalho; a segunda entende a escassez ou ausência de renda como a falta de acesso aos serviços e bens sociais básicos, tais como: moradia, saúde, educação, saneamento básico, energia elétrica etc, em virtude da ausência ou não efetividade das políticas públicas que promovem a exclusão social; a terceira compreende que o conceito de vulnerabilidade não está relacionado apenas à renda ou ao usufruto de bens e serviços sociais, mas, principalmente, às capacidades das famílias e indivíduos. Desse modo,

A pobreza vista como privação de capacidades, sendo pobres aqueles que carecem de competências básicas para atuarem no meio social, que necessitam de oportunidades para conseguir níveis minimamente aceitáveis de concretizações, o que pode independer da renda que os indivíduos detêm (Carneiro, 2005: 71).

Os efeitos citados promovem o que se pode chamar de exclusão social, a qual está relacionada ao desprezo que marcou a história das comunidades negras no período pós-abolicionismo.

A mobilização em torno da autodeclaração da comunidade de Olaria criou um projeto de reconhecimento de quilombolas na Secretaria de Educação de Irará. Esse projeto visava, entre outros objetivos, promover a intervenção jurídico-social para reconhecer todas as comunidades quilombolas do município e, assim, garantir os direitos previstos na Constituição da República Federativa do Brasil. Esse foi um projeto de extensão promovido pela Secretaria de Educação do município que contou com a coordenação do professor Denilson Lima dos Santos. De acordo com as metas do projeto, objetivava-se intervir na realidade social dos quilombolas do município de Irará, de modo a proporcionar o reconhecimento social e jurídico da subjetividade quilombola e promover a efetivação dos direitos reconhecidos constitucionalmente às comunidades remanescentes de quilombos, funcionando a base teórica como orientadora das ações sociais empreendidas no âmbito do projeto de extensão. 
Esse projeto foi desenvolvido por professores do município que atuavam num setor da Secretaria, o qual era denominado de Departamento de Cultura e possuía as seguintes metas ${ }^{14}$ : Promover discussões sobre identidade étnica e memória na região em destaque, a partir de palestras e entrevistas individuais;

Estabelecer os contatos, no que se fizerem necessários, com instituições, a fim de buscar uma possibilidade de celebração de acordo, com órgãos públicos ou privados, como o Instituto Nacional de Colonização e Reforma Agrária, Fundação Palmares, Universidades e Entidades correlatas, visando à troca de elementos e conhecimentos comuns no trato das demandas quilombolas;

Identificar a região geográfica dos antigos quilombos a partir de depoimentos orais e documentos oficiais emitidos, a fim de promover uma possibilidade de demarcação espacial dos sítios quilombolas;

Investigar a partir da memória oral e visual o processo de ocupação das terras dos antigos quilombos;

Reconhecer a partir de dados numéricos os principais sujeitos que residem na região analisada;

Identificar quais são os principais recursos naturais da região, a fim de elaborar um plano de desenvolvimento sustentável local;

Estabelecer a partir da experiência oral as principais manifestações da cultura local;

Promover palestras a partir de temas que tenham as questões de afirmações de cidadania para afrodescendentes a grupos compostos por: crianças, jovens e idosos;

Desenvolver gravação de entrevistas com pessoas idosas da região, buscando informações sobre o surgimento do lugar e o estabelecimento das primeiras famílias;

Buscar informações pertinentes ao processo de atuação de costumes e tradições locais que foram desenvolvidos no espaço vivido;

Colher dados e documentos históricos, que possam subsidiar informações da ocupação espacial dos Remanescentes das Comunidades de Quilombos na região em destaque;

\footnotetext{
${ }^{14}$ Secretaria de Educação Municipal de Irará. Projeto de reconhecimento de comunidades quilombolas, departamento de Cultura, 2008.
} 
Promover debates sobre a busca de direitos sociais adquiridos pelos Remanescentes das Comunidades de Quilombos, através da execução de palestras e seminários que terão como foco principal as políticas públicas relativas aos afrodescendentes;

Organizar grupos locais que possam manifesta-se para representar as causas sociais mais urgentes da comunidade em fóruns, palestras, reuniões e audiências, que tenham as políticas sociais para Remanescentes de Quilombos em metas.

Por meio desse projeto, pretendeu-se gerar bases de uma sistematização para acompanhamento dos laudos periciais a partir das demandas de comunidades negras rurais do município. $\mathrm{E}$, assim, levantar elementos de natureza etnográfica através de casos considerados paradigmáticos que possibilitassem definir critérios para uma avaliação de quilombo, a fim de instrumentalizar a produção de laudos históricos e antropológicos voltados para a consolidação de direitos constitucionais. O projeto de reconhecimento da comunidade de Olaria promoveu processos educativos não formais por meio da dinâmica interna do movimento social através de reuniões, congressos, assembleias, cursos de formação e capacitação, entre outros.

Entre outros objetivos, esse projeto ambicionava promover a formação de pessoas comprometidas com o engajamento político das comunidades quilombolas e com a militância direta das lutas populares. De acordo com o professor Denilson Lima dos Santos, foi preciso realizar esse trabalho, uma vez que os quilombolas não dominavam o conhecimento jurídico presente na legislação ${ }^{15}$ :

Quando iniciamos esse projeto de extensão, tínhamos como objetivo fomentar a organização política das comunidades com $\mathrm{o}$ intuito de conquistarmos $\mathrm{o}$ reconhecimento dessas comunidades. Eles precisavam entender que saíram da condição de sujeitos invisíveis para a condição de sujeito de direito. Esse processo foi bastante proveitoso porque conquistamos a confiança da comunidade. Nesse momento todos entenderam que era preciso elaborar os documentos da autodeclaração, o qual visava a certificação...

\footnotetext{
${ }^{15}$ Ata da Associação dos Moradores da Olaria e Pedra Branca. Reunião que teve como pauta a construção do documento de autodeclaração, enquanto quilombola, realizada no dia 15 de julho 2008.

${ }^{15}$ Depoimento de Edivan dos Santos: professor e estudante de Licenciatura de Educação do Campo da UFRB/ Feira de Santana. Ata da associação dos moradores da Olaria: 15/07/2008.
} 
Essa formação estava articulada para além da preocupação formal, uma vez que essa é estratégica, ou seja, um modelo de educação que visionava a formação de quadros que repensam a organização do próprio movimento e a organização da comunidade. De acordo com Gohn (1999), a educação não formal designa um processo com quatro campos e dimensões ou áreas de abrangência que correspondem aos seguintes aspectos: 1) aprendizagem política dos direitos dos indivíduos enquanto cidadãos; 2) capacitação dos indivíduos para o trabalho; 3) a aprendizagem e exercício de práticas que capacitam os indivíduos para a organização comunitária e 4) a aprendizagem de conteúdos da educação formal em espaços e metodologias diferenciadas. No contexto das comunidades quilombolas de Irará, os espaços e atividades inerentes ao campo da educação não formal são desenvolvidos de forma espontânea ou através das intencionalidades políticas e ideológicas expressas na organização e ação do movimento.

O projeto de reconhecimento de comunidades quilombolas da Secretaria de Educação de Irará foi desenvolvido nas sedes das associações rurais das comunidades que almejavam o reconhecimento como quilombolas. Nas visitas realizadas, os organizadores do projeto do reconhecimento, sobretudo o coordenador do projeto de extensão, organizaram debates sobre o significado de ser quilombola como sendo um grupo étnico-racial, segundo o critério de autoatribuição, com trajetória histórica própria, dotado de relações territoriais específicas, com presunção de ancestralidade negra relacionada com a resistência à opressão histórica sofrida pela escravidão. $\mathrm{O}$ objetivo principal era verificar nesses depoimentos indícios de que os fundadores da comunidade foram ou tiveram alguma ligação com escravos ou ex-escravos.

$\mathrm{Na}$ comunidade da Olaria, os líderes da associação, juntamente com os mediadores externos, dirigiam as reuniões que ocorriam mensalmente. Nos encontros, eles discutiam questões pertinentes à dinâmica da vida local e falavam sobre possibilidades de mudanças na comunidade. Dessa forma, o poder local passou a manipular o discurso da identidade quilombola, na perspectiva de atingir a reparação social e racial dos sujeitos que vivem numa condição de pobreza. Conforme conta Evandro, o presidente da associação rural da Olaria ${ }^{16}$ :

\footnotetext{
${ }^{16}$ Evandro dos Santos Viera. Entrevista concedida no dia 27/04/2010. Grupo focal 04.
} 
Quando a secretaria criou o projeto de reconhecimento das comunidades quilombolas, os professores se aproximaram das pessoas mais velhas. Os mais velhos contaram como a comunidade surgiu. Eles contaram histórias e conheciam e histórias que foram contadas pelos pais e avôs. Eles sempre contavam essas histórias. Até o povo mais novo já conhecia essas histórias, mas ninguém que esses casos contados pelos mais velhos poderiam criar um documento importante, como o projeto do reconhecimento.

Os mediadores da Secretaria de Educação de Irará objetivaram, por meio desse projeto, buscar relatos orais dos sujeitos mais velhos da comunidade, a fim de promover a recuperação história do grupo através das histórias de vida dos sujeitos entrevistados, de modo que os moradores dessa comunidade pudessem fazer uso do conceito de quilombo por meio de uma perspectiva política. Essa experiência do projeto resgatou seu trajeto histórico das comunidades, suas relações com o território reivindicado e o que faz esta comunidade se autodefinir quilombola. Essa mudança da legislação construiu um novo parâmetro da etnicidade nas comunidades quilombolas brasileiras, que passaram a utilizar o jogo das identidades.

Esse projeto instaurou nessas comunidades o fortalecimento do discurso da identidade quilombola do grupo, contribuindo para o engajamento da identidade negra dos moradores e a valorização de sua trajetória até os dias atuais. Os moradores de Olaria abraçaram o projeto desenvolvido pelos agentes da Secretaria de Educação de Irará, uma vez que compreenderam que o reconhecimento das terras de quilombos poderia programar na comunidade algumas políticas sociais criadas para as comunidades quilombolas. Assim, a identidade quilombola está associada à garantia de direitos sociais, os quais conferem o respeito à dignidade. As demandas por reconhecimento da diferença foram articuladas em torno do debate da desigualdade material acentuada, onde ainda faz muito sentido lutar por uma repartição menos desigual das riquezas sociais, isto é, por políticas de redistribuição. Conforme se observa na seguinte fala ${ }^{17}$ :

\footnotetext{
${ }^{17}$ Joemia Xavier, nascida em 10/07/1969, agente de saúde da comunidade, moradora da Olaria e membro do terreiro. Entrevista concedida no dia 15/08/2008.
} 
A gente quer saber por que agora tá dizendo que aqui é um quilombo. Antes, o povo mais velho falava da escravidão e dessa história que os negros se escondiam no mato. Mas, agora, a gente quer saber por que as pessoas se interessaram para dizer que aqui é um quilombo. Eu ouvi na televisão que o quilombola tem direito a vaga na universidade. Eu quero saber como a gente pode ter vaga para estudar na universidade, porque ainda eu sonho em continuar com meus estudos. Além disso, tem outras coisas que sempre aparece na televisão, mas a gente não entende bem o que passa na televisão. A gente quer saber como nós é visto como quilombola e o que a gente pode ganhar com isso...

O discurso de quilombola foi assimilado pelos sujeitos da comunidade como uma possibilidade de transformação do lugar no qual vivem em uma condição de extrema pobreza, já que a falta de recursos materiais, como a terra, nesse município, está associada à condição etnico-racial. Dentre as principais questões que as pessoas almejam, aparecem as seguintes: melhoria e/ou implantação dos serviços de saúde com qualidade nas comunidades; implantação do Programa Saúde da Família; implementação de ações efetivas de detecção e controle da anemia falciforme; atendimento odontológico; cursos que promovam o desenvolvimento das potencialidades dos jovens das comunidades nas áreas de educação e de qualificação profissional; realização de cursos de alfabetização para jovens e adultos; melhor estruturação da escola existente na comunidade com suporte de materiais pedagógicos; reforma e ampliação da escola que existe na região (Escola Municipal Ana Souza Carneiro); transporte escolar com qualidade e segurança para os jovens que estudam fora da comunidade; revitalização do trabalho com a cerâmica; e demarcação das terras que pertenceram aos ancestrais ${ }^{18}$.

Depois da criação do projeto de reconhecimento, os moradores da comunidade da Olaria suscitaram muitas expectativas no sentido da justiça social e da redistribuição da renda. De acordo com a entrevista concedida pelo presidente da associação rural da Olaria, Evandro dos Santos Vieira, pode-se observar o seguinte ${ }^{19}$ :

Nós queremos o reconhecimento da nossa comunidade como quilombola porque a partir disso podemos buscar melhoras para nós. Durante anos morávamos aqui sem grandes expectativas de mudanças, mas de acordo com o que eu venho estudando entendi que ser quilombola é bom! Podemos conquistar melhoras para nossas casas, água encanada, política de geração de renda, e outras que não me lembro agora...Eu só sei que depois disso eu não pretendo mais sair para trabalhar em Salvador como ajudante de pedreiro.

\footnotetext{
${ }^{18}$ Ata da Associação Rural da Olaria e Pedra Branca. Criação do projeto de reconhecimento, 22/03/2009.

${ }^{19}$ Evandro dos Santos Viera. Entrevista concedida no dia 27/04/2010.
} 
Entre os moradores da Olaria, esse processo de reconhecimento foi visto inicialmente como mais um processo criação de políticas que tentam reparar as injustiças de status dos membros da sociedade. Ou seja, a identidade quilombola foi concebida como um elo discursivo que poderia aproximar esse grupo de alguns recursos materiais necessários para a sobrevivência. Em outros espaços brasileiros, a luta pela terra firmou o processo de reconhecimento das comunidades quilombolas. $\mathrm{Na}$ comunidade de Olaria, inicialmente a demarcação da terra não entrou na pauta dos discursos reivindicatórios. Nessa comunidade, o discurso do reconhecimento se apresenta necessariamente ligado à categoria de exploração, verdadeira matriz da desigualdade social.

Nesse momento eles não falavam sobre a demarcação do território, apenas vislumbravam as políticas sociais criadas para os quilombolas no âmbito do Governo Federal. Cabe ressaltar que as demandas da comunidade não se voltaram para a questão da posse da terra. Conforme voz corrente na comunidade, as terras que são habitadas pelos nativos foram doadas pelos ancestrais. Portanto, eles viam como uma consequência natural a exclusão da propriedade fundiária, porque compreendiam que a posse da terra estava relacionada com compra. Ou seja, quem herdou e não comprou mais terras, consequentemente, não teria condições para deixar terras para os seus descendentes. De acordo com essa entrevista, o morador pensa a ideia de propriedade de terras na comunidade de Olaria por meio do seguinte raciocínio ${ }^{20}$ :

As terras que temos aqui foram herdadas do meu pai. O meu pai herdou do meu avô. Eu não tenho nada para deixar para os meus filhos. Como eu vou deixar terras para os meus filhos, se eu tenho cinco filhos e possuo apenas duas tarefas de terras? Aí fica difícil, né? Eu penso, assim: quem não comprou terras não deixa herança. O pobre da roça não tem condições de comprar terras porque mal tem o que comer. Tudo hoje é mais difícil. Na época dos meus avôs as pessoas não comprovam terras. Quem podia cercar, cercava as terras e tomava posse. E foi assim que cercaram as nossas terras lá no passado.

A expropriação fundiária marca a história do grupo, porém os atuais moradores não buscam um projeto de reforma agrária. Eles compreendem que a propriedade da terra só pode acontecer mediante a compra. Essa questão pode ser explicada a partir da compreensão do espaço agrário do município de Irará, o qual é formado por pequenos

${ }^{20}$ UBS. Lavrador, nascido em 13/02/1954. Entrevista concedida em 25/09/2012. 
minifúndios. Ou seja, o destituído da posse da terra não consegue vislumbrar um projeto de reforma agrária nesse município que é composto por pequenas propriedades rurais. Observa-se, tanto nas entrevistas quanto nos documentos, que o projeto de reconhecimento das comunidades quilombolas do município, assim como o projeto da comunidade de Olaria, visou apenas à implementação de políticas de emergências de cunho assistencialista. Todo processo foi construído a partir de ações de mediadores externos que estavam envolvidos diretamente com um partido político. E ação pode ser compreendida como uma política eleitoreira, a qual não objetivou a discussão das desigualdades sociais demarcadas no decorrer da história do grupo, e centrou-se apenas na exaltação dos aspectos culturais e exotização da identidade dos quilombolas.

Entre 2009 e 2010, no discurso conduzido pelos representantes da Secretaria de Educação, a luta por reconhecimento dos remanescentes da comunidade não estava eminentemente relacionada com a busca da identidade cultural. O trabalho produzido pelos funcionários da Secretaria de Educação de Irará se aproximou da construção do discurso étnico, o qual estava relacionado com a cultura afro-brasileira. Esse discurso estava associado à ideia de valorização da cultura e de redistribuição de recursos, sobretudo, de políticas sociais conferidas no âmbito do Ministério de Desenvolvimento Social (MDS) e da Secretaria de Políticas de Promoção da Igualdade Racial (SEPPIR).

A conclusão do projeto de extensão coordenado pela Secretaria de Educação aconteceu no final do ano de 2009. Durante o desenvolvimento do projeto, foram gravados os relatos sobre a história de constituição da comunidade e tiradas cópias de documentos que comprovam a origem da comunidade para a instrução do pedido de seu reconhecimento. Estas informações foram compiladas num documento chamado de Carta de autorreconhecimento. Como a maioria dos moradores dessas localidades é composta de sujeitos analfabetos, entraram em cena as organizações não governamentais como agentes intermediários entre a comunidade e o Estado que implantou a política pública de titulação dos quilombolas. Com o aval da comunidade, a Carta de autorreconhecimento, depois de estruturada, foi enviada para a Fundação Cultural Palmares. Depois de concluída a primeira etapa do projeto, foram remetidos para a Fundação Cultural Palmares os pedidos de inscrição das comunidades quilombolas localizadas no município de Irará no Cadastro Geral de Remanescentes das Comunidades Quilombolas, e emitido o Certificado de autodefinição como Remanescente dos Quilombos. 
No dia 27 de dezembro de 2010, através da Portaria $n^{\circ}$ 162, de 21 de dezembro de 2010 da Fundação Cultural Palmares (FCP), essas comunidades foram certificadas pela FCP e, consequentemente, passaram a ter existência jurídica para o reconhecimento de seus direitos constitucionais. A nova legislação permitiu aos quilombolas as garantias individuais e sociais das pessoas; o regime democrático passou a ser condição para um governo justo e legítimo, através da ampla participação da população em suas instâncias representativas e que tenha como característica indissociável o pluralismo político e, por objetivo, a construção de uma sociedade justa e solidária, sem preconceito de cor, raça, religião e sexo, abolindo todas as formas de discriminação, segundo os artigos $1^{\circ}$ e $3^{\circ}$, da Constituição Federal (Leite, 2000).

Atualmente, os quilombolas do município já obtiveram algumas conquistas, como ressalta o líder comunitário Evandro dos Santos Vieira ${ }^{21}$ :

\begin{abstract}
Depois do reconhecimento, várias coisas já mudaram aqui na comunidade da Olaria e outras comunidades: aqui nós já temos água encanada e quem não tem água encanada tem cisternas; quem não tinha luz elétrica já adquiriu pelo programa Luz para Todos; conquistamos o programa de distribuição de alimentos; a comunidade da Tapera, além dessas conquistas, também adquiriu uma fábrica de polpa de frutas; os jovens das comunidades estão na universidade; no semestre passado, só da comunidade de Tapera, foram 9 jovens que entraram na $\mathrm{UEFS}^{22}$ a partir das cotas para quilombolas e lá eles moram na residência dos quilombolas. Os jovens que entraram na Universidade Federal do Recôncavo no curso de Educação do Campo conquistaram uma bolsa de 800 reais... Qual o jovem da roça que hoje tem um salário desses? Mas precisamos ainda de outras melhorias. Agora estamos tentando promover a titulação das terras para buscarmos o Programa Minha Casa, Minha vida.
\end{abstract}

Observa-se nesse discurso que o processo de reconhecimento das comunidades quilombolas de Irará aproximou seus moradores de direitos e políticas sociais que projetam a correção da pobreza e o desenvolvimento da cidadania. Porém, as comunidades quilombolas do município têm pela frente um longo caminho de lutas para garantir os direitos que ainda não foram conquistados. No discurso de Evandro Vieira, há a necessidade de maior rapidez no que se refere à titulação de seus territórios. Esse novo processo demanda mobilização dos grupos e dos novos atores sociais, os quais visam assegurar os direitos alcançados depois do reconhecimento. De acordo com o discurso de Evandro, a luta do reconhecimento uniu as comunidades; mas, atualmente esses encontros não acontecem com a mesma frequência. $\mathrm{O}$ mesmo sugere um novo

\footnotetext{
${ }^{21}$ Evandro dos Santos Vieira. Presidente da Associação Rural dos Moradores da Olaria e Pedra Branca. Entrevista concedida em 25/11/2013.

${ }^{22}$ Universidade Estadual de Feira de Santana.
} 
engajamento, visando à demarcação do território, a qual é produzida pelo INCRA. Depois da conclusão das etapas do projeto de extensão coordenado pela Secretaria de Educação, os medidores externos não frequentam as comunidades como frequentavam durante o período de 2008 a 2010. Contudo, observa-se que os líderes locais já estão promovendo a articulação dessas comunidades.

\section{Considerações Finais}

A construção do projeto de reconhecimento das comunidades estudadas agenciou a coordenação dos movimentos sociais em questão, os quais apontavam que o reconhecimento da identidade quilombola era o caminho viável para as comunidades que enfrentavam uma história caracterizada pela vulnerabilidade social. Por outros caminhos, o discurso do etnodesenvolvimento chegou também aos mediadores que articularam o projeto de reconhecimento dessas comunidades do Portal do Sertão da Bahia, particularmente discutido entre os representantes dos partidos políticos e do movimento do sindicato rural junto às comunidades quilombolas. $\mathrm{Na}$ medida em que nossa abordagem era aprofundada, ocorria a identificação das diferentes lógicas de ação mobilizadas na mediação. Nesse momento, era imprescindível justificar ações, intenções, comportamentos e discursos políticos, a fim de remeter a uma multiplicidade de gramáticas e modelos de mediação. Nota-se que ocorreu uma dominância de um modelo baseado na ética da interlocução, tornando-se acessível à participação da população-alvo nas diversas fases do projeto.

Essa nova construção de lideranças quilombolas na região pesquisada se aproximou dos projetos que visavam à elaboração e aplicação de políticas públicas para quilombolas, dentre os quais se podem destacar os representantes do Estado, da sociedade civil, e da própria comunidade beneficiária da titulação das chamadas "terras remanescentes de quilombos". No conjunto de problemáticas que estamos levantando, convém ainda destacar a noção vaga de "interesse da comunidade", visto que unifica uma multiplicidade de acondicionamentos pouco formalizados e em constante processo de reconstituição. Quanto à escolha do mediador junto às instâncias de fora da comunidade, ela nem sempre coincidiu com a da liderança constituída na comunidade. O status social do mediador reconhecido junto aos comunitários não estava estritamente perpetuado a desempenhos de liderança. 
Observou-se que, durante esse processo, aconteceu a construção de um espaço de mediação assim como a proposta do agir comunicativo pressupõe. Nesse caso, a memória e a identidade quilombola entraram como matéria na gramática das metodologias participativas. Os mediadores externos, aqueles que dominam a gramática que faz falar a cultura quilombola, apropriaram-se dos discursos políticos, jurídicos e acadêmicos para mobilizar a comunidade. Os mediadores promoveram uma articulação entre as agências do Estado e a cultura quilombola, as quais foram subsumidas ao mundo comum da cultura da mediação participativa.

Esses novos discursos expressaram de forma explícita a preocupação com a injustiça e as desigualdades sociais, reivindicando políticas públicas para diminuir a pobreza e combater os efeitos da discriminação. Esse modelo de reconhecimento aproxima-se do modelo de status, no qual o não reconhecimento se consolida quando as instituições estruturam a interação de acordo com normas culturais que impedem a paridade de participação, e a interação é regulada por um padrão institucionalizado de valoração cultural que constitui algumas categorias de atores sociais como normativas e outras como deficientes ou inferiores.

Para além de ser quilombola, essas pessoas almejaram uma justiça social. Essa comunidade passou por um processo de marginalização que é perceptível no cotidiano das pessoas e no enfrentamento das dificuldades materiais de existência. Essas situações geraram outros processos de discriminação e preconceitos, além dos procedimentos históricos de usurpação de suas terras. Além de todos esses processos de marginalização, esse povo sofre também com a inexistência de projetos que financiem as produções agrícolas e com a escassez de chuvas - determinantes que dificultam o trabalho e a produção. Nesse caso, a etnicidade é conduzida na redefinição dos fenômenos étnicos de natureza política ou econômica, remetendo a grupos de pessoas unidas em torno de interesses comuns (Cohen, 1969; 1974). Nesse contexto, as reivindicações socioeconômicas são deslocadas em favor das de natureza cultural. Considerando esse aspecto de luta por reconhecimento, porém, sem se esquecer da importância que a desigualdade econômica possui dentro da estrutura de justiça, Axel Honneth e Nancy Fraser são dois dos principais autores que se propõem a trabalhar tal conceito de forma sistemática e aprofundada. Dessa forma, o reconhecimento é uma categoria utilizada para realizar o debate sobre as desigualdades sociais e, por fim, a questão da identidade e da diferença é acionada. Em torno da articulação da identidade 
quilombola, as lutas fomentadas na busca das políticas promovem uma espécie de politização generalizada da cultura, especialmente quanto às lutas por identidade e diferença.

Desde o início do ano de 2007, através de toda uma rodada de convenções sobre políticas públicas para as comunidades quilombolas, vem se intensificando a mobilidade de mediadores oriundos delas mesmas. Dispositivos de regulação das conexões em rede entre os atores voltados para a comunidade e as estruturas estatais de onde emanam os recursos de execução dessas políticas têm sido sistematicamente reclamados na forma de questionamentos às intervenções de mediadores externos. Mais do que apenas uma ética dialógica, suspeitamos que os quilombolas têm demandado a substituição de mediadores externos por aqueles oriundos da própria comunidade.

Os diversos atores sociais produzem discursos a partir dos embasamentos políticos, jurídicos e/ou acadêmicos e, assim, promovem disputas pelo poder de definição no mundo social. Os discursos sobre o conceito de quilombola, consequentemente, formaram uma atuação política que ganhou colocações distintas, a depender dos lugares de onde eram emanados e praticados, uma vez que o universo discursivo é também um universo concorrencial, sobretudo em se tratando de articulação de movimentos sociais. O discurso sobre a concepção de quilombolas gerou uma forma de ação do sujeito sobre o mundo, onde se demarca uma posição e se disputa o público receptor. Dessa forma, considera-se que a construção do discurso de autorreconhecimento de comunidade quilombola não pode ser entendida como um produto individualizado, posto que está a todo momento dialogando com outros, seja numa relação conflitiva ou harmoniosa.

No decorrer do período, nota-se que esse processo formou o quilombola como um mediador político, a partir da capacitação desenvolvida. Mais tarde, lideranças locais se apropriaram dos discursos externos e produziram uma argumentação de capital político. Para além da emergência dos novos atores políticos, sujeitos de direito, os quilombolas passaram também a disputar e conquistar cargos de liderança com representação na esfera política institucionalizada das relações locais. Pode-se verificar que os projetos implementados favoreceram a promoção de mediadores locais à condição de representantes políticos vinculados à esfera dos partidos. 
Por fim, nota-se que o atual processo de atribuição de direitos das comunidades quilombolas brasileiras deu origem a uma arena privilegiada para refletir acerca dos diversos discursos que são produzidos em torno do processo de reconhecimento dos quilombolas. A ideia de reconhecimento e redistribuição articulou discursos que se aproximam do conceito de Estado multicultural, o qual tem com meta assegurar determinados direitos diferenciados de grupos minoritários. A articulação do projeto de reconhecimento, ao levar em conta, em grande parte, os anseios e as demandas da comunidade, instaura nas comunidades uma esfera pública específica. A participação, tanto no que diz respeito à concepção quanto ao gerenciamento e à execução das atividades do projeto, pressupõe que agentes do Estado e membros da comunidade ajam comunicativamente.

\section{Referências}

ARRETCHE, Marta. Dossiê Agenda de Pesquisa em Políticas Públicas. Revista Brasileira de Ciências Sociais, Vol.18, n 51, p. 07-10, 2003.

ATA DA ASSOCIAÇÃO DOS MORADORES DA OLARIA E PEDRA BRANCA. Reunião que teve como pauta a construção do documento de autodeclaração, enquanto quilombola, realizada no dia 15 de julho 2008.

BARZOTTO, Luis Fernando. Justiça social: gênese, estrutura e aplicação de um conceito. Revista Direito \& Justiça - Faculdade de Direito - PUCRS, n. 28, 2003.

CARNEIRO, Carla Bronzo Ladeira. Concepções sobre pobreza e alguns desafios para a intervenção social. Revista Social e Sociedade, n. 84, p. 66-90, 2005.

FRASER, Nancy. Da Redistribuição ao Reconhecimento? Dilemas da justiça na era póssocialista. Trad. Marcia Prates. In: SOUZA, Jessé (org.). Democracia hoje: novos desafios para a teoria democrática contemporânea. Brasília: Editora, Universidade de Brasília, 2001.

GOHN, Maria da Glória. Educação não formal e o educador social. Atuação no desenvolvimento de projetos sociais. São Paulo: Cortez, 2010.

HONNET, Axel. Luta por reconhecimento. A gramática moral dos conflitos sociais. São Paulo: Editora 34, 2003.

IVO, Anete L. A "destituição" do social: Estado, governo e políticas sociais. Caderno CRH, Salvador, n. 35, p. 41-84, jul./dez. 2001.

MINISTÉRIO DO DESENVOLVIMENTO SOCIAL E COMBATE À FOME. Bolsa Família: cidadania e dignidade para milhões de brasileiros. Brasília: MDS, 2010.

MST, O que queremos com as escolas do acampamento. Caderno de formação número 18 , $3^{\text {a }}$ edição, Editora Pares, 1999.

BRASIL. Programa Brasil Quilombola. Diagnóstico de Ações Realizadas, Brasília, SEPPIR, Julho de 2004. Julho de 2005.

Programa Brasil Quilombola. Diagnóstico de Ações Realizadas, Brasília, SEPPIR, Julho de 2006.

Programa Brasil Quilombola. Diagnóstico de Ações Realizadas, Brasília, SEPPIR,

Diagnóstico de Ações Realizadas, Brasília, SEPPIR, Julho de 2007.

Programa Brasil Quilombola. Diagnóstico de Ações Realizadas, Brasília, SEPPIR, Julho de 2008. 

Julho de 2009.

Programa Brasil Quilombola. Diagnóstico de Ações Realizadas, Brasília, SEPPIR, Julho de 2010.

Programa Brasil Quilombola. Diagnóstico de Ações Realizadas, Brasília, SEPPIR,

Diagnóstico de Ações Realizadas, Brasília, SEPPIR, Julho de 2012.

TELLES, Edward. Racismo à brasileira: uma nova perspectiva sociológica. Rio de Janeiro: Relume-Dumará: Fundação Ford, 2003.

Recebido em: 01/11/2015.

Aprovado em: 28/03/2016. 